\title{
Microspore Embryogenesis
}

\author{
Tara D. Silva \\ University of Colombo \\ Sri Lanka
}

\section{Introduction}

Microspores are the precursors of the male gametes of plants and are equivalent to spermatids of animals. Microspores develop into pollen grains within the anthers of a flower in angiosperms. Mature pollen grains are the male gametophytes. The function of the male gametophyte is to participate in the sexual reproduction of plants.

Quite separate from this intended pathway of gametogenesis, a microspore can also be induced to assume sporophytic development. "Totipotency", which is unique to plant cells, allows a microspore that is already destined to develop into a male gametophyte, to redirect its development pathway so that a haploid sporophyte is regenerated under specified conditions. The cellular totipotency displayed by the microspore is considered an adaptive mechanism for survival that is brought about under stressful environmental conditions (Bonet et al. 1998). The process that leads to the development of a sporophyte from a microspore is referred to as microspore embryogenesis (or pollen embryogenesis). It is also commonly termed androgenesis.

Androgenesis rarely occurs in nature, but is relatively easily induced in several plant species under in vitro conditions. The first report on regeneration of androgenic plants was in the Solanaceous species, Datura innoxia, where Guha and Maheshwari (1964) demonstrated that the anthers cultured in vitro yielded haploid plants. Following this initial discovery, many attempts have been made to repeat the success in other plant species. Early studies were mostly empirical and were directed at identifying suitable culture media, pre-treatment conditions that are required for inducing sporophytic development in microspores, and other such practical considerations. Since then, much progress has been made, particularly toward the understanding of the basic processes that occur at cellular level with the switching of developmental pathway of the microspore, from gametogenesis to microspore embryogenesis. Concerted efforts on many different plants have resulted in the documentation of the microspore embryogenesis process in over 250 species (Maluszynski et al. 2003), even though achieving success with androgenesis is still restricted to annuals and herbaceous or non-woody plants mostly. The two main techniques that are employed to generate androgenic plants in vitro are the anther culture and the microspore (pollen) culture methods. Anther culture is the more widely applied, where the excised immature anthers dissected out from flower buds are cultured whole on suitable growth media under appropriate in vitro conditions. The microspores inside the anther develop into plants through a process by which their normal gametophytic development is stalled and 
sporophytic development is initiated. As the microspores are endowed with only one set of chromosomes instead of the two sets present in the somatic cells of the diploid plant, the pollen-derived plants are haploid. In the anther culture method, even though the goal is to produce plants of microspore origin, there is a danger of plants regenerating from somatic tissue of the anther wall rather than from the haploid microspore cells. In the microspore culture technique, individual pollen cells isolated from anther tissue are placed directly in culture. It is possible to isolate microspores by mechanical means such as crushing of anthers and release into medium by magnetic stirring. They can also be isolated as naturally shed microspores in the culture medium after pre-culture of anthers. Although microspore culture is technically more demanding and is less efficient in some plant species than the culture of whole anthers, it has several advantages over anther culture. Mainly it eliminates the danger of plant development from anther wall tissue. As individual plants develop from separate pollen cells, the chance of chimera production is also low. Further, the culture of individual microspores makes possible the tracing of events that occur from microspore initiation through to embryogenic development, by cell tracking studies allowing for the greater understanding of the process of androgenesis in plants.

Haploid plants are weak and sterile and have no regular means to produce sexual progeny. Therefore, haploid plants by themselves serve no useful purpose. However, haploid plants regenerated from cultured anthers or microspores can afterwards be brought back to the normal diploid state by duplicating their chromosome number through application of chemicals such as colchicine, or other in vitro techniques. The resulting plants will have two identical chromosome sets and be perfectly homozygous, and therefore will give rise to fertile homogenous progenies. Thus, the usefulness of the technique is not in deriving haploid plants but in producing doubled haploids or dihaploids. The great interest in androgenesis among the scientific community, particularly among those involved in practical plant breeding, is this perceived potential of the technique to rapidly develop homozygous lines in the breeding material, which otherwise would require several generations of inbreeding through conventional procedures. The effectiveness of the technique depends on the efficiency of haploid plant regeneration from microspores contained within the anthers, and the conversion of these haploids to doubled haploid plants either spontaneously during the tissue culture phase or induced thereafter. With this method, true-breeding lines are produced in the immediately succeeding generation, and thus the technique has immense utility for developing homozygous breeding lines in a relatively short period.

The objective of this Chapter is to detail out the process of microspore embryogenesis in plants and discuss the factors that influence its induction, particularly with reference to the recent progress made in the understanding of molecular events that occur during the reprogramming of the microspore development pathway.

\section{Gametogenesis versus embryogenesis}

In normal gametogenesis, the diploid microsporocytes or pollen mother cells in the anther undergo meiotic division to yield haploid microspores. Each uni-nulceate microspore then divides mitotically to produce a cell with two haploid nuclei, which is the bi-nucleate state of pollen. Cytokinesis that follows produces two cells that are of unequal size. The larger cell 
is termed the vegetative cell and the smaller one is known as the generative cell. The generative nucleus divides again by mitosis to produce two haploid sperm nuclei. The vegetative nucleus remains without further division. Thus a mature male gametophyte at the time of affecting fertilization is often bi-cellular (and sometimes tri-cellular) with three haploid nuclei of which two nuclei of the generative cell origin participate in the "double fertilization" that is characteristic of angiosperm reproduction, producing the diploid zygote and the triploid endosperm of the seed.

In contrast, the embryogenic development of a uni-nucleate microspore that is induced in vitro, is usually initiated by a symmetric mitotic division that results in two equal-sized cells. Further mitotic divisions result in a group of undifferentiated cells, and their rapid proliferation gives rise to a multi-cellular mass. Depending on the in vitro conditions provided, the multi-cellular structures may become embryogenic or remain meristematic. Embryogenic cells, following further division and pattern-formation, are able to develop into structures referred to as somatic embryos. The microspore-derived somatic embryos are initiated as globular structures, and become heart-shaped, and with further morphogenesis become torpedo-shaped and finally develop into cotyledonary embryos with bipolar embryo axes, mimicking closely the zygotic embryo development process. Under some in vitro conditions, regeneration of shoots and roots may occur directly from proliferating callus through a process of organogenesis without producing somatic embryos. The regenerated plants may possess a haploid chromosome complement, similar to the microspore cell of origin, or the chromosome number may have doubled during cycles of cell division, to give rise to doubled haploid plants that are completely homozygous.

\section{Conditions under which microspore embryogenesis can be induced}

To deviate from the normal pathway of gametogenesis and for re-direction towards a pathway of embryogenesis, a microspore has to be subjected to specific conditions. The conditions that are required to induce such developmental reprogramming will obviously vary with the species, and often within a species among its genotypes or varieties also. Nevertheless, several key factors have been recognized that positively influence the microspore embryogenesis induction in a variety of plant species. In Table 1 these various

\begin{tabular}{|l|l|}
\hline $\begin{array}{l}\text { Broad categorization of factors } \\
\text { influencing microspore } \\
\text { embryogenesis }\end{array}$ & Specific effects \\
\hline \multirow{2}{*}{ Of the anther donor plant } & Genotype, variety or species \\
\cline { 2 - 2 } & $\begin{array}{l}\text { Physiological status - influenced by the growth } \\
\text { condition, including seasonal effects such as day } \\
\text { length, light, temperature etc. }\end{array}$ \\
\hline Of the microspore & Developmental stage, pollen genotype \\
\hline Of the pre-culture environment & Pre-treatments \\
\hline Of the in vitro culture conditions & Culture media \\
\cline { 2 - 2 } & Incubation conditions \\
\hline
\end{tabular}

Table 1. Factors affecting microspore embryogenesis 
biotic and abiotic factors, that have a strong bearing on the ability of a microspore to undergo embryogenesis, are grouped into factors of the anther donor plant, the microspore, pre-culture environment and of the in vitro culture condition.

\subsection{Genotype}

Often, the in vitro androgenic response is genotype-dependent, and culture conditions may have to be optimized for each genotype. Even of the same species, different varieties and genotypes respond vastly differently to induction attempts. For example, in rice, japonica varieties are known to be more responsive than indica types (Yan et al. 1996), while within each ecotype considerable variation exists between varieties in their anther culture responsiveness (Silva and Ratnayake 2009). Plant regeneration occurs from cultured microspores usually in two stages. Initially the microspore divides and proliferates into an undifferentiated cell mass, followed by pattern formation and morphogenesis that lead to shoot regeneration which occurs through embryogenesis (or sometimes organogenesis). Inheritance studies on anther culture ability have shown that in many species these two processes are genetically determined independent events, and whether any of the two processes or both would occur during anther culture is determined to a large extent by the genetic makeup of the cells. The stimulation of these two events often requires different conditions, and is likely controlled by different genes. Experimental evidence suggests that the mode of inheritance is quantitative in nature (Silva 2010 and references therein). No sustained efforts have been made to actually breed the trait, anther culture ability into anther culture-recalcitrant genotypes, perhaps due to the complexities of the genetic control of in vitro response. Nevertheless the possibility of transferring the trait through sexual hybridization remains a viable prospect. On the other hand, the existence of a large nongenetic component of variation for anther culture ability suggests that there is sufficient scope for improving anther culture efficiency through the manipulation of these non-genetic factors that include the culture media components and pre- and post-culture conditions.

\subsection{Physiological status of the anther donor plant}

The number and the vigor of microspores found within the anther, the nutritional status of the tissues of the anther, the endogenous levels of growth regulators, may to some extent be influenced by the physiological age and growth condition of the donor plant, which in turn will have a bearing on microspore embryogenic competence. Seasonal variations in anther response have been observed in wheat and barley (Datta 2005). Differences in competence of the cultured microspores to assume embryogenic development when anthers are collected from field grown plants and when harvested from pot plants bear further testimony to the influence of the parent plant growth condition on their microspore embryogenic competence (Datta 2005, Silva 2010). It is common practice in anther culture to use anthers from the first or early flush of flowers rather than anthers from buds in later branches or tillers of the plant. The physiology of the donor plant can be altered, and the androgenic response improved, when the donor plant is carefully nurtured and grown under favorable environmental conditions, although pest control measures may have a detrimental effect on in vitro microspore response. Critical environmental factors include light intensity, photoperiod, temperature, nutrition and carbon dioxide concentration. Seasonal variations in the anther response have also been observed, which is probably also related to the overall growth of the donor plant. 


\subsection{Microspore development stage}

The microspore development stage is a complex factor that has a strong influence on the success of anther culture. The exact stage of the microspore that responds to inductive treatment varies with the species, and is restricted to a relatively narrow developmental window. Only microspores that are at a stage sufficiently immature can be induced to change course from a gametophytic pre-programme to embryogenic re-programming leading to sporophytic development. Even though all microspores within an anther would be roughly of a similar age, the incremental differences in the stages of development of individual microspores can be considered significant, in setting each apart with regard to their embryogenic competence. Therefore, even within the same anther only a percentage of pollen cells would undergo divisions leading to their embryogenic development. For many species, the most amenable stage is either the uni-nucleate stage of the microspore or, at or just after the first pollen mitosis, which is the early bi-nucleate stage. At this time the transcriptional status of the microspore may still be proliferative and not yet fully differentiated (Malik et al. 2007). More mature microspores are considered irreversibly committed to gametogenesis and are at points of no return in their programme of maturation into male gametophytes.

In the practical implementation of the anther culture technique, it is necessary to identify easily, the flower buds that need to be harvested in order to collect microspores at the correct stage of maturity that is appropriate for in vitro culture. In many species, a maturity gradient is observed in flower buds within the inflorescence that displays either an acropetal or basipetal developmental succession. Therefore, a series of buds taken from different positions on the inflorescence (or in the case of individual flowers, buds of different sizes) need to be pre-examined in order to identify the stage of microspore development within their anthers. This is done by squashing anthers to release pollen, and staining with acetocarmine to observe the nuclei under the light microscope. DAPI (4', 6-diamidino-2phenylindole) may be also used to stain the nuclear DNA, which can then be visualized using a fluorescent microscope. Such pre-examination will be very useful to establish a correlation between an easily observable morphological trait, (e.g. the petal to sepal length ratio in tobacco) with the pollen development stage, to be used as a quick guide to identify flowers that would have anthers carrying microspores at the required stage of maturity.

\subsection{Pre-treatment stresses}

For almost all the plant species in which anther culture has been attempted, it is common to include a physical or chemical pre-culture treatment that is applied to excised flower buds, whole inflorescences or separated anthers. The pre-treatment is required to trigger the induction of the sporophytic pathway, thereby preventing the development of fertile pollen through the gametophytic pathway. A variety of microspore pre-treatment stresses have been tested and found to enhance pollen embryogenesis, although the type, duration and the time of application of these pre-treatments may vary with the species or even the variety. The more commonly used anther or microspore pre-treatment conditions are temperature (cold or heat shock), sucrose and nitrogen starvation, centrifugation, as well as the use of microtubili disruptive agents such as colchicine. Lesser known stress-treatments include irradiation, use of high humidity, anaerobic treatment, electro-stimulation, high medium $\mathrm{pH}$, ethanol and heavy metal treatment. These pre-treatments may be classified 
into three categories based on their application as widely used, neglected and novel (Shariatpanahi et al. 2006). The more notable stress treatments that promote androgenesis are discussed below.

Temperature pre-treatment: A commonly used pre-treatment to induce androgenesis in microspores is the low temperature shock. Cold pre-treatment is usually carried out at $4-10$ ${ }^{\circ} \mathrm{C}$ for a few days up to several weeks. For example in rice, for many varieties, a $10{ }^{\circ} \mathrm{C}$ pretreatment of harvested panicles for 10 - 30 days is sufficient to trigger androgenesis. Several other cereal species including barley, wheat, oat and triticale require low temperature treatment of the excised spikes or flower buds in order to induce microspore embryogenesis. Different views exist on how cold pre-treatment affects the development of the microspore, some or all of which may be relevant to a given species. It is believed that the cold treatment delays the degeneration of anther wall tissues thereby protecting the microspores within, from toxic compounds released by the degenerating maternal tissues. It has also been suggested that at cold temperatures there is greater survival of embryogenic pollen grains leading to enhanced levels of embryogenesis than would occur without pre-treatment. A further explanation is that microspores in the cold pre-treated anthers disconnect from the tapetum resulting in starvation, causing them to switch from gametophytic pathway to embryogenic development. Also, it has been noted that in cold pre-treated anthers the total content of free amino acids is increased, which is suggestive of metabolic re-programming that a microspore needs to undergo, in preparation for embryogenesis induction. Following cold treatment, small heat shock protein genes have been shown to be expressed in tomato and it has been argued that this is possibly to protect cells against chilling injury. The different explanations (Shariatpanahi et al. 2006 and references therein) are based on observations and experiences with different plant species, and the exact mode of action (or actions) is still to be unraveled convincingly.

High temperature has been also used to trigger microspore embryogenesis in certain species. The method is applied routinely with the isolated microspore culture of rapeseed. Embryogenesis is induced efficiently and synchronously in rapeseed microspores subjected to $32{ }^{\circ} \mathrm{C}$ heat shock for about 8 hours, whereas normal gametogenesis occurs at $18{ }^{\circ} \mathrm{C}$ under otherwise similar conditions. High temperature induced microspore embryogenesis does also occur in wheat (Touraev et al. 1996b) and tobacco (Touraev et al. 1996a). As with cold shock, different mechanisms have been proposed to explain the basis of microspore induction through high temperature treatment. It is known that several heat shock proteins (HSPs) are synthesized in various plant tissues in response to elevated temperatures, which have a role in protecting cells from thermo-damage (Schoffl et al. 1996). This is considered an adaptive mechanism since plants are unable to escape extreme environmental conditions due to their immobility. Amongst the HSPs, members of HSP 70 are the most abundant and evolutionarily conserved while HSP 90 is also abundant and is constitutively expressed in eukaryotes with a specific role in heat stress (Chug and Eudes 2008). Synthesis of HSPs has been observed in heat-stressed microspores also, and HSP 70 was suggested to inhibit apoptosis (Jaattela et al. 1998). Even though much significance was attached earlier to the HSPs, for their considered role in enabling microspore embryogenesis (Cordewener et al. 1995, Zarsky et al. 1995, Touraev et al. 1996), subsequent studies have proved that embryogenesis can be induced in rapeseed microspores even when HSPs are not synthesized. For example, embryogenesis can be induced in rapeseed microspores that are 
stressed with microtubule de-polymerizing agent, colchicine also (Zhao et al. 2003) and this proves that HSPs are not essentially required. Since plants reportedly produce HSPs in response to a variety of other environmental stresses such as cold, drought, heavy metal stress, and starvation (Schoffl et al. 1998, Zarsky et al. 1995), it is more likely that HSPs have an overall protective role that allows the cells to survive during the periods of adverse environment conditions, and embryogenesis may simply be the consequence of blocked pollen development (Zhao et al. 2003). In rapeseed microspores, the heat shock is believed to also cause microtubule and cytoskeleton rearrangements that lead to altered cell cycle events during microspore culture (Simmonds and Keller 1999).

Nitrogen and sugar starvation: Nutrient starvation, particularly of nitrogen and sugar, has been effective in enhancing the in vitro anther response in some species. Nitrogen starvation may be applied to the anther donor plant or the excised anthers and microspores. The mother plant can be nitrogen-stressed by restricting the application of nitrogen fertilizer to the plant. Excised anthers can be starved of nitrogen by withdrawing or limiting the inorganic and organic nitrogen sources in the initial culture media. In several species, isolated microspores have shown a better embryogenic response with nitrogen starvation. For example, with tobacco pollen, a high rate of embryogenic induction was achieved from starving the microspores of glutamine, by an initial period of growth on glutamine free medium (Kyo and Harada 1986). Also in tobacco, sucrose and nitrogen starvation of pollen of the mid bi-cellular stage resulted in embryogenic induction and yielded a high number of embryos when transferred to a simple medium containing sucrose and nitrogen (Touraev et al.1997). Similarly sucrose starvation at $25^{\circ} \mathrm{C}$ resulted in the efficient formation of embryogenic microspores in tobacco when transferred to sugar containing medium (Touraev et al. 1996a). In wheat, the culture of excised anthers under starvation and heat shock conditions induced the formation of embryogenic microspores at high frequency (Touraev et al. 1996b). During starvation, cytoplasmic and nuclear changes have been observed in the microspores including de-differentiation of plastids, changes in chromatin and nuclear structure, changes in the level of RNA synthesis and protein kinase activity, and the activation of small heat shock protein genes (Shariatpanahi et al. 2006 and refereces therein).

Centrifugation: Subjecting anthers to centrifugation pre-treatment has been useful to improve the efficiency of microspore embryogenesis. In tobacco anthers, a four-fold increase in the regeneration of haploid plants was reported following centrifugation of the anthers prior to culture, although the maturity stage of the microspores determined the degree of success (Tanaka 1973). Experiments with chick pea (Cicer arietinum) also appear to suggest that centrifugation may have a positive impact on embryo initiation from cultured anthers, even though the response is variety specific (Grewal et al. 2009). Because the appropriate centrifugal force and the duration of treatment vary with the microspore development stage and variety, it is difficult to standardize protocols for centrifugation pre-treatment.

Colchicine: The use of colchicine for microspore pre-treatment has been reported to be effective in enhancing microspore embryogenesis in rapeseed (Zaki and Dickinson 1991, Zhao et al. 1996), wheat (Barnabas 2003a), coffee (Herrera et al. 2002) and maize (Obert and Barnabas 2004). Colchicine acts by binding to $\alpha$ - and $\beta$-tubulin heterodimers thereby inhibiting further dimer addition to microtubules, which causes de-polymerization of the microtubule (Sternlicht et al. 1983). During normal gametogenesis of pollen, the peripheral 
position of the nucleus is maintained by microtubules and actin filaments (Hause et al. 1992). The de-polymerization of the microtubules causes a shift in the nuclear position from the cell periphery to cell center leading to altered cell polarity. This may eventually result in a symmetric division in place of the asymmetric division that is the standard for first pollen mitosis (Zhao et al. 1996), and maybe the trigger that directs microspores onto the sporophytic pathway. It is also suggested that when colchicine prevents dimer addition to a- and $\beta$-tubulin heterodimers, the excess of free tubulins that remain in the cell will inhibit the synthesis of new molecules, some of which may be specifically required for pollen development (Carpenter et al. 1992). Thus, normal gametogenesis is suppressed and embryogenesis is initiated.

From the above account it becomes clear that the microspores can be induced to become embryogenic under a variety of different stresses. The kind of stress to be applied will depend on the plant species. However, more than one stress treatment will work with microspores of some species, particularly in relation to the stage of microspore development at the time of induction. For example, in rapeseed, severe heat stress $\left(41^{\circ} \mathrm{C}\right)$ is required to induce efficient embryogenic development in late bi-nucleate microspores (Binarova et al. 1997), mild heat stress ( $32{ }^{\circ} \mathrm{C}$ ) to induce late uni-nucleate to early bi-nucleate staged microspores (Ferrie and Keller 1995), whereas uni-nucleate microspores at an earlier stage of development corresponding to vacuolated stage are induced more effectively with colchicine (Zhao et al. 1996). Similarly, in tobacco bi-cellular pollen is easily induced under sucrose and nitrogen starvation pre-treatment conditions (Garrido et al. 1995, Kyo and Harada 1986) whereas microspores at the uni-nucleate stage are induced under heat shock (Touraev et al. 1996a), and centrifugal pre-treatment (Tanaka 1973), although the latter two pre-treatments have little influence in inducing embryogenesis from bi-cellular pollen. Accordingly, through careful experimentation and judicious choice of pre-treatments, it would be possible to induce microspores of a wider developmental range than anticipated before, towards successful embryogenic re-programming.

\subsection{Culture medium}

As with all other in vitro culture systems, successful induction of embryogenesis from cultured microspores or anthers depends to a large extent on the composition of the culture medium. The requirements of a given species are identified mainly through an empirical process of trial and error. The source of carbon, macronutrients (particularly the form in which nitrogen is supplied in the medium) and micronutrients may determine if embryogenesis will be initiated or not. The type and concentration of the growth regulators, particularly the auxins and cytokinins, as well as their interactive presence can be the deciding media factor that would influence pollen embryogenesis. Standard media have been developed for different species although specific genotypes may have their individual requirements. The more widely used basal media for anther culture are the N6 (Chu 1978), Nitsch and Nitsch (1969), MS (Murashige and Skoog 1962) and B 5 (Gamborg et al. 1968). These media are used often in their original form, but sometimes modified by supplementing or subtracting one or more components to better suite a given plant species or genotype. With more recalcitrant species, new media will have to be formulated that are tailor-made to address their specific requirements. 
Carbon source: The carbon source is an important component in tissue culture media that provides the energy required for the growth of the cultured explants. The most frequently used carbon source in tissue culture media is sucrose. Sugars also play a significant role in regulating the osmotic pressure in the culture media, although this would be secondary to its main role as the source of energy. Plants belonging to the families Poaceae and Brassicaceae require fairly high sucrose levels $(6-17 \%)$ for the induction of microspore embryogenesis (Dunwell and Thurling 1985), whereas more regular lower concentrations (2 - 5\%) are used with Solanaceous species (Dunwell 2010). Since of late, maltose has come to replace sucrose as the major carbon source in cereal anther culture, usually at $6 \%$ in the induction medium and at half this strength in the regeneration medium (Wedzony et al. 2009). Maltose in the anther culture medium is degraded more slowly than sucrose and yields only glucose upon hydrolysis whereas sucrose is metabolized very rapidly into glucose and fructose. Fructose is known to have a detrimental effect on embryoid production in wheat anther culture (Last and Brettell 1990, Navarro-Alvarez et al. 1994). The reduced efficiency of androgenesis observed in the presence of sucrose as the carbon source maybe due to the sensitivity of microspores to fructose that is generated from the hydrolysis of sucrose in the culture medium. Further, the superiority of maltose over other sugars such as glucose, fructose and mannitol, has also been proven with rice anther culture (Bishnoi et al. 2000, Lentini et al. 1995). Exogenously supplied carbohydrates in the culture medium may also in part fulfill the osmotic requirements of the cells growing in vitro. Nevertheless, results indicate that the type of sugar to be used is more important as an energy source rather than in osmotic regulation of the medium. On the other hand, certain sugar alcohols such as mannitol and sorbitol have been used in microspore culture media purely for their role in osmo-regulation. Both mannitol (Raina and Irfan 1998) and sorbitol (Kishore and Reddy 1986) have had beneficial effects on rice anther culture.

Nitrogen source: Nitrogen can be supplied to the culture medium in the inorganic or organic form. The inorganic nitrogen is usually introduced in the form of nitrate or ammonium ions while nitrogen in the organic form can be supplied as vitamins and amino acid supplements. Often, anther cultures may require more than one form of the nitrogen and the correct balance of the different sources of nitrogen may be very important for successful androgenesis. For example, Chu (1978) demonstrated that the level of nitrogen in the form of ammonium ions was critical for androgenesis in rice, on which basis he developed the $\mathrm{N} 6$ medium with appropriate concentrations of $\left(\mathrm{NH}_{4}\right)_{2} \mathrm{SO}_{4}$ and $\mathrm{KNO}_{3}$. While the N6 medium has become the most widely used for rice anther culture, particularly of the japonica types, the nitrogen requirement of the indica rice varieties was proved to be somewhat different. For indica rices, lowering the level of $\left(\mathrm{NH}_{4}\right)_{2} \mathrm{SO}_{4}$ and increasing the concentration of $\mathrm{KNO}_{3}$ was shown to produce better anther response and green plant regeneration from anther-derived callus (Raina and Zapata 1997).

Micronutrients: Micronutrients play an important and sometimes a crucial role in normal plant growth and development. Deficiency symptoms arise in plants that are grown under sub-optimal levels of micronutrients. As such, the tissue culture media are also formulated with the inclusion of essential micronutrients. However, in depth studies of their influence on in vitro cell culture, particularly microspore embryogenesis, are limited. This neglect is in spite of their absolute requirement for many physiological and biochemical cellular processes, including the catalysis of enzymatic reactions. Two of the micronutrients that 
have been investigated for their influence on microspore embryogenesis are copper and zinc. The addition of copper sulphate in the anther pre-treatment medium allowed green plant regeneration from an otherwise exclusively albino plant producing recalcitrant barley cultivar (Jacquard et al. 2009, Wojnarowiez et al. 2002).

\subsection{Incubation conditions}

The temperature at which the cultures are incubated, light / dark conditions, the density of anthers or microspores in a culture vessel and other such post culture environmental conditions may have a subtle effect on the success of microspore embryogenesis, depending on the plant species or genotype. The temperature at which anther cultures are incubated has been shown to be an important factor in rice (Okamoto et al. 2001). However, very few investigations have been carried out to manipulate culture temperatures for enhanced anther culture efficiency. Light is another environmental factor that has a bearing on anther culture success because it is a stimulus that influences in vitro pollen morphogeneis (Reynolds and Crawford 1997). Generally, anther or microspore cultures are maintained in the dark during the initial phase of culture, particularly when regeneration occurs through callus, and transferred to illuminated conditions at a later stage. For some plant species diurnal alternation of incubation for several hours in the light and then darkness has been beneficial (Germana et al. 2005, Sunderland 1971). However, optimal conditions need to be determined for each system.

\section{Cellular changes that occur at the initiation of microspore embryogenesis}

Basic studies on microspore embryogenesis have been dealt with in detail in a few plant species only, that are considered model systems for generating haploid plants from cultured microspores. The following descriptions pertaining to the changes that occur in the microspores under induction conditions are therefore based largely on the work carried out on these model plant systems, namely; Brassica napus (rapeseed), Hordeum vulgare (barley), Nicotiana tobaccum (tobacco) and Triticum aestivum (wheat).

A microspore in which embryogenic development is initiated will display characteristic features that will distinguish it from a normal microspore that is developing into a male gametophyte. These distinguishing features have been observed to be common among many of the plant species that have been subjected to detailed study, and therefore may be adopted as cellular markers of pollen embryogenesis, allowing the development of a unified model for the microspore embryogenic induction process. The changes associated with the de-differentiation process of the microspore include changes in cellular morphology and biochemical processes as well as changes in gene expression profiles.

\subsection{Changes in the cellular landscape of microspores during embryogenic induction}

Following stress treatment, microspores that have been induced to become embryogenic become enlarged. The enlargement of stress-induced microspores in comparison to the relatively smaller size of the normal microspores is generally taken to be associated with their acquisition of embryogenic competence (Maraschin et al. 2005a), although all the cells that enlarge may not continue in the embryogenic pathway of development. 
During early development, a normal microspore that is released from the tetrad has its nucleus located in the center of a cytoplasm-rich cell. Subsequently a vacuole develops and expands to occupy a large part of the cell, which pushes the cytoplasm with the embedded nucleus to the periphery of the cell. In the young microspores that are induced to assume embryogenic development, there is re-positioning of the nucleus from its peripheral location to the center of the cell and the large vacuole gets broken up by radial strands of cytoplasm creating several smaller vacuoles giving the cell a star-like appearance. This stellar morphology of the cell is considered to be one of the early markers that portend reprogramming of the microspore for switching from gametogenesis to embryogenic development and has been observed during the embryogenic induction in the four androgenic model systems; barley, wheat, rapeseed and tobacco irrespective of whether the embryogenic induction occurs in the uni- or bi-nuclear stage microspores (Zaki and Dickinson 1991, Touraev et al. 1996, Indrianto et al. 2001, Maraschin et al. 2005).

\subsection{Cytoskeletal rearrangements and changes to division symmetry}

During normal development of the uni-nucleate microspore, the peripheral position of the pollen nucleus is maintained by cytoskeletal components; the microtubules and actin filaments (Hause et al. 1992). In stress-induced microspores, the re-positioning of the nucleus from the periphery of the cell to its center is considered to be associated with cytoskeletal re-arrangements. The fact that the destruction of the cytoskeleton by colchicine can induce pollen embryogenesis, of which process an initial manifestation is the migration of the nucleus, supports this proposition (Zaki and Dickinson 1991, Zhao et al. 1996, Gervais et al. 2000, Obert and Barnabas 2004). The central nuclear positioning is believed to confer radial polarity in the cell, initiating a symmetric division that results in two equal-sized cells. The plane of division is equatorial and is similar to what is observed in mitotically activated somatic cells (Segui-Simarro and Nuez 2008). Further subsequent divisions eventually lead to the formation of a multi-cellular pro-embryo. This is in contrast to what occurs during the normal process of gametogenesis. In normal pollen development the peripheral nucleus of the uni-nucleate microspore undergoes the first pollen mitosis which is an asymmetric division yielding two cells of distinctly different sizes. The vegetative cell is large and contains bulk of the pollen cytoplasm allowing its nucleus to assume a more central position in the pollen grain. The smaller generative cell, with its arch-shaped cytoplasm, remains close to the intine wall surrounded by the vegetative cell cytoplasm. The nucleus of the smaller generative cell undergoes a second mitotic division to yield the two fertilizing nuclei that carry out the double-fertilization event characteristic of the angiosperms.

However, it must be noted that the division symmetry is not a mandatory requirement for embryogenesis initiation in the microspore. For example, treating maize pollen with colchicine, although allows embryogenic induction, does not result in division symmetry (Barnabas et al. 1999). This appears to suggest that the role of cytoskeletal inhibitors on embryogenic induction in microspores is not confined to the triggering of symmetric divisions alone. Also in some plant species, stress-induced pollen embryogenesis occurs at the bi-nucleate stage, at which time the pollen cell has already undergone an initial asymmetric division, resulting in two very unequal-sized cells. This does not preclude embryogenic development in bi-nucleate $B$. napus microspores when subjected to heat shock at $32{ }^{\circ} \mathrm{C}$ (Custers et al. 1994) and in late bi-nucleate pollen by an extra heat shock treatment at $41^{\circ} \mathrm{C}$ (Binarova et al, 1997). 
As with colchicine pre-treatment, heat and cold shock have been identified to produce cytoskeletal rearrangements in microspores leading to the migration of the nucleus to the cell center, with resultant initiation of embryogenic development (Binarova et al. 1997, Wallin and Stromberg 1995). Several other stress treatments that have the ability to induce embryogenesis also affect cytoskeletal rearrangements in the microspore and the migration of the nucleus to the center of the cell.

\subsection{Biochemical changes and cytoplasmic re-modeling}

In normal pollen development following the first pollen mitosis, the large vacuole gets reabsorbed. The larger vegetative cell accumulates food reserves such as carbohydrates (starch), lipids and proteins, as well as RNA (Touraev et al. 1997) that powers the pollen tube's growth during its passage through the style to reach the female gametophyte. The generative cell contains much less stored products and fewer organelles. With embryogenic induction, changes occur in the cytoplasm. The cytoplasm becomes more alkaline in contrast to the slightly acidic $\mathrm{pH}$ that is observed in the normal microspores (Pauls et al. 2006). There is destruction of cellular organelles such as the plastids, and a decline in the synthesis of ribosomes along with a decrease in the accumulation of starch grains and lipid bodies. Thus there is an overall clearing of the cytoplasm which is suggestive of a state of dedifferentiation of the microspore in preparation for the re-programming events that would follow with the initiation of embryogenic development.

Based on these observations it has been proposed that stress leads to the dedifferentiation of microspores by the repression of gametophytic development. It was believed that this reprogramming was only possible in microspores that were still at a very early stage of development, and in many experimental systems this stage corresponded to the late uninucleate to the early bi-nucleate stage of the microspore. It was also generally accepted that androgenesis could no longer be triggered in bi-nucleate pollen cells in which starch and lipid accumulation has already occurred. The starch-filled cells were deemed irreversibly committed to gametogenesis. However, more recent evidence suggests that this window of opportunity could be made much wider than initially anticipated by precisely timing the application of the stress treatment and the type of stress (Touraev et al. 1997). For example, in B. napus an extra heat treatment allows even the late binucleate pollen to undergo embryogenic development.

There are two main pathways by which cytoplasmic remodeling occurs in normal eukaryotic cells. Autophagy is the process by which the destruction of cellular organelles occurs via lysosomes. The destruction of cellular molecules, both long- and short-lived ones, occurs through the ubiquitin $26 \mathrm{~S}$ proteosomal pathway. Both these pathways are developmentally regulated, but maybe activated by subjecting cells to stress such as heat shock, cold shock and starvation. Autophagial activity mediated by lysosomes in which cellular organelles are destroyed, has been observed to occur in early embryogenesis of $N$. tobaccum microspores (Sunderland and Dunwell 1974). H. vulgare microspores in which embryogenic development has been induced by stress have shown expression of genes coding for enzymes of the ubiquitin 26S proteosomal pathway (Maraschin et al. 2005).

\subsection{Nuclear rearrangements}

In the normal microspores, at the two-celled stage, the vegetative and generative nuclei perform different functions. The vegetative cell concentrates on accumulating metabolites. 
In keeping with this function, its nucleus shows high transcriptional activity and contains diffused chromatin. In contrast, the generative cell which is in preparation for a second mitotic division displays greater chromatin condensation in readiness for mitosis and is transcriptionally less active. Changes in the nuclear organization and content are observed in embryogenically induced microspores when compared with microspores that are developing into mature pollen grains. These include changes to patterns of chromatin condensation, nucleolar activity and transcriptional activity of the nucleus. Following the first symmetric division, the two cells of the embryogenic microspores typically display nuclear organization and function that are characteristic of mitotically active cells, such as condensed chromatin patches and compacted nucleoli (Germana 2011). With regard to nuclear DNA content, the doubling of the normal number of chromosomes may be observed. This appears to be a consequence of the in vitro culture conditions, and depending on the species or the genotype, may not compulsorily occur. In the event that chromosomal doubling does occur, the mechanism is believed to be nuclear fusion in the main, and this would normally occur at the initial stages of embryogenic divisions (SeguiSimarro and Nuez 2008).

\section{Changes in gene expression}

The microspore embryogenesis has been established to work precisely under defined conditions in four plant species, namely Brassica napus (rapeseed), Hordeum vulgare (barley), Nicotiana tobaccum (tobacco) and Triticum aestivum (wheat). The reliability with which these species lend themselves to the induction process and the unerring regularity and repeatability of success have allowed these plants to emerge as model systems on which basic studies of the microspore embryogenesis process has been pivoted. In the last decade or so, findings from the burgeoning expansion of genomic, proteomic and metabolomic research and their tools have been applied also to understand the fundamental processes leading to the switching of pathways in pollen development from gametogenesis to embryogenesis, and in the search for genes that are responsible for this turn-around.

Molecular and gene expression studies on microspore embryogenesis have been largely dealt with in the four model plants; wheat, barley, rapeseed and tobacco. This is mainly because of the repeatability and efficiency of the well-established protocols that are available in these plant species for embryogenesis induction from cultured microspores or anthers.

Early studies on molecular aspects have concentrated on identifying genes that are differentially expressed in embryogenic and non-embryogenic microspores. These studies have helped to understand the cellular processes that take place during the transition of the microspore to embryogenic development, from its original gametophytic developmental program. More recently, genomics and bioinformatics approaches have been implemented for gene discovery and functional characterization of candidate genes, whose expression appear to be associated with the embryogenic re-programming in the stress-induced microspores. Once elucidated, the genes that are identified to be expressed in common among different plant species during the initiation of embryogenesis and its progression towards embryo development, may be used as markers for early detection of the embryogenic induction process. 


\subsection{Genes expressed during barley microspore embryogenesis}

In barley microspores, embryogenic induction can be achieved in up to $50 \%$ of the microspores by subjecting the cells to a combined mannitol stress and starvation treatment, and thus, the barley microspore embryogenic system provides a very good platform to study differential gene expression (Maraschin et al. 2005b).

In an early study by Vrinten et al. (1999), differential screening of a cDNA library prepared from mannitol-induced 3 day old barley microspores identified three genes that were expressed during embryogenesis initiation. The genes were functionally characterized as encoding a non-specific lipid transfer protein (ECLTP), glutathione-S-transferene (ECGST) and an arabinogalactan-like protein.

A more detailed study involving the screening of mRNA populations of uni-nucleate microspores about to undergo the first pollen mitosis, bi-cellular pollen, and stress-induced embryogenic microspores against microarrays of Expressed Sequence Tags (ESTs) derived from early stages of barley zygotic embryogenesis was carried out by Maraschin et al. (2006) in order to elucidate the gene expression profiles associated with each development programme. Following Principle Component Analysis (PCA) of the normalized gene expression data, it was revealed that in uni-nucleate pollen, mRNAs related to mitotic division and lipid biosynthesis were detected mainly. In bi-cellular pollen induction of genes involved in carbohydrate and energy metabolism were observed. In contrast, the embryogenic pollen displayed the expression of genes involved in protein degradation, starch and sugar hydrolysis, stress responses, inhibition of programmed cell death, metabolism and cell signaling. The gene expression profiles of stress-induced embryogenic microspores point to metabolic changes including proteolysis that appears to relate to the de-differentiation process of the induced microspores. Proteolysis is considered to play an important role in a regulatory mechanism in all cell differentiation and cell cycle progression in plant cells (Hellman and Estelle 2004) and is involved in many aspects of plant development including somatic and zygotic embryogenesis, germination, tissue remodeling and programmed cell death (Beers et al. 2004). In microspore embryogenesis whether pollen specific proteins are degraded by the expression of genes coding for proteolytic enzymes, allowing the cells to deviate from pre-programmed gametogenesis to assume embryogenic development, remains to be proved.

\subsection{Molecular basis of wheat microspore embryogenesis}

Differential gene expression between stress-induced microspores and freshly isolated pollen has been studied in wheat using the Suppression Subtractive Hybridization of cDNA clones. These screens have yielded a number of differentially expressed genes (Hosp et al. 2007). Nearly one third of the genes that were differentially expressed could be assigned to functional categories based on similarity with database sequences, while the others were of unknown function or without significant matches to database sequences. A majority of the annotated sequences were found to have a metabolic function which again points to significant biochemical and physiological changes that occur during the switch from gametogenesis to embryogenesis.

A gene that has been identified to be differentially expressed between late-stage microspore derived embryos and mature pollen is one that encodes a cysteine-labeled metallothionine 
(EcMt) (Reynolds and Crawford 1996). EcMt was thus indicated as a marker for microspore embryogenesis although it is also induced following Abscisic Acid (ABA) treatment in diverse tissue.

\subsection{Tobacco microspore embryogenesis}

In tobacco, genes encoding phosphoproteins (NtEP) have been isolated from embryogenic microspores which were shown to have selective expression in de-differentitating pollen (Kyo et al. 2002). In a subsequent study Kyo et al. (2003) isolated 16 cDNAs that were differentially expressed in embryogenic pollen of tobacco. Of these, 13 transcripts were expressed in de-differentiating pollen while the other three were observed in dedifferentiating microspores as well as in cell populations undergoing active division. The genes whose expression was confined to de-differentiating pollen included the earlier observed gene coding for NtEP, stress induced genes including ABA-responsive genes, genes coding for Myb transcription factor, glucanase \& chitinase, and some unknown genes. Genes that were expressed in both type of cells, the de-differentiating and dividing cells, coded for histones and a mini-chromosome maintaining protein.

Subtraction hybridization of cDNA derived from stress-induced microspores and normal pollen indicated that several genes, involved in metabolism, chromosome re-modeling, (transcription and translation) were up regulated in the induced microspores.

\subsection{Rapeseed microspore embryogenesis}

The discovery of genes involved in B. napus (rapeseed) microspore embryogenesis has relied to a great extent on the genomic data of its close taxonomic relative, Arabidopsis thaliana. A. thaliana is considered a model organism for genome and transcriptome studies since its genome is fully sequenced and a large number of its genes identified and functionally annotated. Transcriptome analysis of A. thaliana microspores has been carried out in detail and the genes involved in regulating the microspore development towards a male gametophyte have been characterized. However, in the absence of a protocol to initiate embryogenic development in A. thaliana microspores, there has not been the opportunity to leverage the wealth of genome and transcriptome data on normal gametogenesis, in establishing the genes that are differentially expressed during microspore embryogenesis. On the other hand, the availability of such a well-characterized genome resource, with a good deal of genome-wide similarity and identity among orthologous genes between the two species, Arabidopsis and Brassica, has meant that $A$. thaliana genome resource could be used as a reference database in the discovery of genes that are expressed during embryogenesis re-programming in rapeseed microspores, and differential screens of gene expression profiles between Arabidopsis and Brassica have produced fruitful interpretations.

An early study on differential gene expression between 4 day heat stressed embryogenic and non-embryogenic microspores of rapeseed identified five different cDNAs that were up regulated in the induced microspores (Boutilier et al. 2002). Two of these encoded BURP domain proteins with unknown function (Hattori et al. 1998), the third encoded an AP2/EREBP domain transcription factor which has since been named BABY BOOM (BBM), the fourth cDNA encoded the orthologue of the Arabidopsis AKT1 $\mathrm{K}^{+}$channel protein (Sentenac et al. 1992), while the last sequence was one to which no open reading frame had 
been assigned. Of these, the genes coding for BURP domain proteins were found to be expressed through out microspore and zygotic embryogenesis in rapeseed, with highest intensity during the initial period of storage product accumulation. BBM gene was found to be expressed in the early stages of microspore and zygotic embryogenesis. Over-expressing the BBM gene with a constitutive promoter resulted in the ectopic induction of somatic embryos from seedling tissue in rapeseed and Arabidopsis, suggesting a vital role for this gene in embryogenic induction. Further studies have successfully isolated a number of genes that are expressed during later stages of microspore embryo development, one of which is a gene encoding a CLAVATA3/ESR (CLE) family member, CLE 19. In zygotic and microspore embryogenesis the expression of this gene is restricted to globular and heartshaped embryo development stages. This gene encodes a small secreted protein that is considered to promote cell differentiation and inhibit meristem formation in a range of plant organs (Fiers et al. 2004). Transcriptome analysis of different stages of microspore-derived embryo development has confirmed that there is gradual transition from pollen-dominated expression profiles to embryo-eclipsed profiles in mature cultures (Custers et al. 2001).

Genes that were differentially expressed during microspore embryogenesis in rapeseed have been isolated by subtractive hybridization, and a subtracted cDNA library constructed (Tsuwamoto et al. 2007). After sequencing over 2000 clones that showed differential expression in embryogenically-induced and non-embryogenic microspores, the non redundant sequences selected were searched against the well annotated Arabidopsis Munich Information center for Protein Sequences (MIPS) database to identify functional categories of the differentially expressed genes. When characterized, many sequences related to embryo-specific genes, the most frequent among them being the gene coding for Lipid Transfer Protein (LTP). Although the detailed function of LPTs is mostly unknown, several genes encoding LTPs have been found to be expressed in different embryogenic systems such as zygotic embryos in maize (Sossountzov et al. 1991), somatic embryos in carrot (Sterk et al. 1991), and microspore-derived embryos in barley (Vrinten et al. 1999), suggesting that it has a definite role in the embryogenesis process. In addition, ESTs of genes that code for napin and cruciferine (seed storage proteins in Brassica), oleosin (a major component of oil bodies) and phytosulfokine have been identified as being up-regulated during embryogenic induction. A detailed analysis of the expression patterns of 15 selected genes, determined by quantitative real-time reverse transcription-polymerase chain reaction (RT-PCR), found all of them to be highly expressed in the early stages of microspore embryogenesis, but poorly expressed in microspores when freshly isolated (before induction) or cultured under non-embryogenic induction conditions. The Principle Component Analysis based on the expression profiles of the 15 genes placed them in two groups; those having high expression during androgenic initiation and those expressed in the early to middle stage (globular to torpedo stage) of embryogenesis.

Malik et al. (2007) conducted a detailed examination of transcript profiles of embryogenic microspores and pollen-derived embryos in B. napus that represented a developmental series, starting from fresh pollen $(0 \mathrm{~d})$ to pollen after $3 \mathrm{~d}$ (induced), $5 \mathrm{~d}$ (dividing microspores), and $7 \mathrm{~d}$ stress treatments. Based on the $A$. thaliana information resource, they described ESTs that were most abundant at each stage. According to this study, microspores after a $3 \mathrm{~d}$ stress treatment have lost gene transcripts associated with protein synthesis (40 S and $60 \mathrm{~S}$ ribosomal proteins, initiation and elongation factors). These transcriptional changes 
may well relate to the cytoplasmic clearing of the de-differentiation process. In the cDNA libraries derived from microspore cultures following $3 \mathrm{~d}$ to $5 \mathrm{~d}$ stress treatments, a large number of pollen specific transcripts (pectinesterase, exopolygalactouronase, Bnm1, BP4) were isolated. However, it was not clear if these expression profiles were observed because the cultures may still have contained microspores that were not induced but were developing into mature pollen, or because during the period of transition, from pollen development to early stages of embryo induction, there was parallel expression of both pollen- and embryo-specific genes. A transcript that was abundant in all stages of development after induction $(3 \mathrm{~d}, 5 \mathrm{~d}$, and $7 \mathrm{~d}$ ) was Bnm1 (invertase / pectin methylesterase inhibitor). This has been earlier shown to be expressed in the early stages of microspore embryogenesis in rapeseed up to globular stages (Treacy et al. 1997). In the $5 \mathrm{~d}$ and $7 \mathrm{~d}$ cultures, AGP gene transcripts were abundant. AGPs are a large multi-gene family coding for glycosylated Hyp-rich proteoglycans. While no specific function has been determined for AGPs, at least some AGPs have been implicated in the regulation of somatic embryogenesis (Chapman et al. 2000) and microspore embryogenesis (Letarte et al. 2006). In the $7 \mathrm{~d}$ microspore cultures, LTP were frequent. The LTP are able to transport phospholipids across cell membranes and are required for functioning of several biological processes such as embryogenesis, defense reaction, adaptations to stress and cutin formation (Kader 1996, Wang et al. 2005). LTPs are expressed in both somatic and zygotic embryos (Sterk et al. 1991). The cDNA libraries constructed from 5-day dividing and 7-day embryogenic microspores contained a number of ESTs for BnCYP78A whose functions are still not known.

From the various analyses of gene expression profiles carried out with stress induced microspores of the four model species, copious amount of data has been generated and is continued to be produced on the different types of genes that are found to be turned on or differentially expressed between the two developmental pathways of the microspore. Although a lot of concentration has been applied in trying to determine the genes that are involved in regulating the stress-induced embryogenic response in microspores and to understand the gene expression patterns that follow, the information gathered from the model species is far from complete at present, and thus elude a unified scheme whereby one could predict the expression of a common cascade of genes that would cause the switching of pathways from gametogenesis to embryogenesis that result in embryo development. Given the complexity of development re-programming that would have had to occur, and considering that there are different pathways by which embryogenesis is induced in microspores of different species, it is not surprising that a clear overall picture has not emerged yet.

However, the genes that have so far been identified as being specifically up-regulated during pollen embryogenesis have been broadly categorized into three main groups; stress responsive genes, gametogenesis-repressive genes and embryogenesis-related genes with functions identified as below.

\subsection{Stress responsive genes}

During microspore embryogenesis the up regulation of the Head Shock Protein (HSP) genes is observed, not only in response to heat stress but also other stresses applied on 
microspores such as starvation and colchicine. However, a distinct role for HSP on microspore embryogenesis has yet to be clearly established.

\subsection{Gametogenesis repressive genes}

Suppression of the gametophytic development must occur in the microspore before the genes for embryogenesis can be switched on (Hosp et al. 2007). Accumulation of starch in the microspore signifies that the cell has embarked on a gametophytic pathway of development where as the inhibition of starch accumulation portends the initiation of embryogenesis. The genes involved in starch synthesis and accumulation are seen to be down regulated during embryogenesis (Maraschin et al. 2006).

\subsection{Embryogenesis related genes}

Microspore embryogenesis occurs in a pattern of morphogenesis akin to zygotic embryo development. Based on this similarity, embryo pattern regulators such as members of the gene family 14-3-3 of barley have been observed to be up regulated, both in time and space (Maraschin et al. 2003).

\section{Development of a multi-cellular pollen embryo}

An induced microspore will undergo several rounds of mitotic divisions that result in a number of cells, contained together bounded by the exine or the outer wall of the microspore. There can be different pathways by which muli-cellular structures are produced from an initial star-like microspore. The four basic routes, based on the symmetry of the initial division of the microspore, as described by Razdan (2003) are as follows.

Pathway I: The initial division of the uni-nucleate microspore is symmetrical and results in two cells of equal size. Each of these cells undergoes further divisions producing a ball of cells within the exine.

Pathway II: An asymmetric initial division produces two cells of unequal size. The ball of cells may originate from the continued division of the larger vegetative cell while the smaller generative cell may divide a few times before degenerating.

Pathway III: Following an initial asymmetric division, the generative cell divides successively yielding the multi-cellular state. The vegetative cell remains arrested in division.

Pathway IV: Following an initial asymmetric division, both vegetative and generative cells will be equally active and divide to give rise to the multi-cellular structure.

The first pathway is considered to be the more common, and is observed in many species that are capable of embryogenic initiation from uni-nucleate microspores, prior to the first pollen mitosis (Smykal 2000). Apart from the stage of microspore development (uni- or binucleate) at which it transits from gametogenesis to embryogenesis, it is also possible that the genotype or the plant species, as well as the stress conditions applied to induce embryogenesis in the microspore may also be factors that determine the pathway of cell division that leads to the development of multi-cellular structures from star-like microspores. 
Irrespective of the above early pattern of microspore divisions, the embryogenic multicellular structures ultimately burst out through the restraining pollen wall, gradually assuming the form of a globular embryo akin to the globular stage of the zygotic embryo. A distinct outer layer of cells that surround a core of meristematic cells is the usual cellular anatomy that is observed in the microspore embryo at early stages of its development. The two types of cells differ in cellular morphology and metabolic processes that distinguish their developmental competences. The cells in the peripheral layer are vacuolated and filled with starch grains, which is suggestive of their differentiated nature, whereas cells to the interior are cytoplasm-filled and devoid of starch deposits which indicates their undifferentiated state and which are in fact capable of further meristematic activity (Barany et al. 2010a). Differences in the organization of cell wall components, particularly the distribution of polysaccharides, have also been noted and linked with the changes that occur in the cellular developmental processes. In microspore-derived embryos of Capsicum annum (pepper), cells in the peripheral layer contain a higher level of de-esterified pectins as wall components, a feature that is common with the cell wall of the mature pollen grain which is committed to normal gametogenesis. On the other hand esterified pectins are found in the cell walls of proliferating inner cells of the microspore embryo as with the walls of very young microspores prior to their gametophytic commitment (Barany et al. 2010b). Thus, the esterification of pectins in the cell walls may be considered as a cellular marker of their state of de-differentiation or meristematic activity, and therefore being capable of subsequent reprogramming towards embryogenic development.

During further development, the microspore-derived globular embryos will follow the normal stages of post-globular embryogeny as seen in zygotic embryo development. As such, passage through heart-shaped and torpedo-shaped stages will culminate in the development of cotyledonary-staged mature somatic embryos that are ready to germinate into full-fledged sporophytic plants.

Alternatively, the multi-cellular mass that is liberated from the rupture of the microspore wall may proliferate to form a callus, from which organogenesis occurs by the regeneration of shoots and roots following transfer to culture media with appropriate growth regulators. It may sometimes be possible to obtain androgenic haploids either via embryo formation or organogenesis from callus in the same species by the manipulation of the chemical components of the culture medium.

\section{References}

Barany I, Fadon B, Risueno MC and Testillano PS. 2010a. Microspore reprogramming to embryogenesis induces changes in cell wall and starch accumulation dynamics associated with proliferation and differentiation events. Plant Signaling and Behavior 5(4):341 - 345.

Barany I, Fadon B, Risueno MC and Testillano PS. 2010b. Cell wall components and pectin esterification levels as markers of proliferation and differentiation events during pollen development and pollen embryogenesis in Capsicum annum L. Journal of Experimental Botany 61(4):1159 - 1175.)

Barnabas B. 2003a. Protocol for producing doubled haploid plants from anther culture of wheat (Triticum aestivum L.). In: Maluszynaki M, Kasha KJ, Forster BP, Szarejko I. 
(eds.). Doubled haploid production in crop plants, a manual. Kluwer Academic Publishers, Dordrecht, The Netherlands, pp $65-70$.

Barnabas B, Obert B, Kovacs G. 1999. Colchicine, an efficient genome doubling agent for maize (Zea mays L.) microspores cultured in anthero. Plant Cell Reports 18:858 862.

Beers EP, Jones AM, Dickerman AW. 2004. The S8 serine, C1A cysteine and A1 aspartic protease families in Arabidopsis. Phytochemistry 65:43 - 58.

Binarova P, Hause G, Cenklova V, Cordewener JHG, van Lookeren Campagne MM. 1997. A short severe heat shock is required to induce embryogenesis in late binuclear pollen of Brassica napus L. Sexual Plant Reproduction 10:200 - 208.

Bonet FJ, Azhaid L \& Olmedilla A (1998). Pollen embryogenesis: atavism or totipotency? Protoplasma 202:115 - 121.

Boutilier K, Offringa R, Sharma VK, Kieft H, Ouellet T, Zhang L, Hattori J, Liu CM, van Lammeren AA, Miki BL, Custers JB, van Lookeren Campagne MM. 2002. Ectopic expression of BABY BOOM triggers a conversion from vegetative to embryonic growth. Plant Cell 14:1737 - 1749.

Carpenter IL, Ploense SE, Snustad DP, Silflow CD. 1992. Preferential expression of an atubulin gene of Arabidopsis in pollen. Plant Cell 4:557 - 571.

Chu C. 1978. The N6 medium and its application to anther culture of cereal crops. In: Proc Symp Plant Tissue Culture. Science Press, Peking, pp 43 - 50.

Chugh A and Eudes F. 2008. Isolated microspore embryogenesis in cereals: aspects and prospects. In: Recent advances in plant biotechnology and its applications. Ed. KH Neumann, A Kumar and SK Sopory. IK International Publishing House, Pvt. Ltd., New Delhi. p 205 - 226.

Cistue L, Riomas A, Castillo AM and Romagosa L. 1994. Production of a large number of doubled haploid plants from barley anthers protected with high concentration of mannitol. Plant Cell Report 13:709 - 712.

Cordewener JHG, Hause G, Gorgen E, Busink R, Hause B, Dons HJM, Van Lammeren AAM, Van Lookeren Campagne MM and Pechan P. 1995. Changes in synthesis and localization of members of the 70-kDa class of heat-shock proteins accompany the induction of embryogenesis in Brassica napus L. microspores. Planta 196:747 - 755.

Custers JBM, Cordewener JHG, Fiers MA, Maasen BTH, van Lookeren Campagne MM, Liu CM. 2001. Androgenesis in Brassica: a model system to study the induction of plant embryogenesis. In: Bhojwani SS, Soh WY (Eds). Current trends in the embryology of angiosperms. Kluwer Academic Publishers, Dordrecht. Pp. 451 - 470.

Custers JBM, Cordewener JHG, Nollen Y, Dons JJM, van Lookeren Campagne MM. 1994. Temperature controls both gametophytic and sporophytic development in microspore cultures of Brassica napus. Plant Cell Reports 16:267 - 271.

Datta SK. 2005. Androgenic haploids: factors controlling development and its application in crop improvement. Current Science 89(11):1870 - 1878.

Dunwell JM. 2010. Haploids in flowering plants: origins and exploitation. Plant Biotechnol. J. 8:377 - 424.

Dunwell JM and Thurling N. 1985. Role of sucrose in microspore embryo production in Brassica napus ssp. Oleifera. J. Exp. Bot. 36:1478 - 1491.

Fiers M, Hause G, Boutilier K, Casamitjana-Martinez E, Weijers D, Offringa R, van der Geest L, van Lookeren Campagne M, Liu CM. 2004. Mis-expression of the CLV3/ESR- 
like gene CLE 19 in Arabidopsis leads to a consumption of root meristem. Gene 18:37 -49 .

Herrera JC, Moreno LG, Acuna JR, Pena MD, Osorio D. 2002. Colchicine-induced microspore embryogenesis in coffee. Plant Cell Tiss Org Cult 71:89 - 92.

Gamborg OL, Miller RA, Ojima K. 1968. Nutrient requirement suspension cultures of soybean root cells. Exp Cell Res 50:151 - 158.

Garrido D, Vicente O, Heberle-Bors E, Isabel Rodriguez-Garcia M. 1995. Cellular changes during the acquisition of embryogenic potential in Nicotiana tobaccum. Protoplasma 186:220 - 230.

Germana MA. 2011. Anther culture for haploid and doubled haploid production. Plant Cell Tissue and Organ Culture 104:283 - 300.

Germana MA, Chiancone B, Iaconia C, Muleo R. 2005. The effect of light quality on anther culture of Citrus clementina Hort. Ex Tan. Acta Physiol Plant 27(4B):717 - 721.

Gervais G, Newcomb W, Simmonds DH. 2000. Re-arrangement of actin filament and microtubule cytoskeleton during induction of microspore embryogenesis in Brassica napus L. cv. Topas. Protoplasma 213:194 - 202.

Grewal RK, Lulsdorf M, Croser J, Ochatt S, Vandenberg A and Warkentin TD. 2009. Doubled haploid production in chick pea (Cicer arietinum L.): role of stress treatments. Plant Cell Rep 28:1289 - 1299.

Guha S. and Maheshwari SC. 1964. In vitro production of embryos from anthers of Datura. Nature 204:497.

Hause G, Hause B, van Lammeren AAM. 1992. Microtubular and actin filament configurations during microspore and pollen development in Brassica napus cv. Topas. Canadian Journal of Botany 70:1369 - 1376.

Hattori j, Boutilier K, van Lookeren Campagne MM, Miki BL. 1998. A conserved BURP domain defines a novel group of plant proteins with unusual primary structures. Mol Gen Genet 259:424 - 428.

Hellmann H and Estelle M. 2004. Plant development: regulation by protein degredation. Science 297(5582):793 - 797.

Hoekstra S, van Zijderveld MH, Louwerse JD, Heidekamp F, van der Mark F. 1992. Anther and microspore culture of Hordeum vulgare L. cv. Igri. Plant Science 86:89 - 96.

Hosp J, Maraschin SF, Touraev A and Boutilier K. 2007. Functional genomics of microspore embryogenesis. Euphytica 158:275 - 285.

Indrianto A, Barinova I, Touraev A, Heberle-Bors E. 2001. Tracking individual wheat microspores in vitro: identification of embryogenic microspores and body axis formation in the embryo. Planta 212:163 - 174.

Jaattela M, Wissing D, Kokholm K, Kallunki T, and Egeblad M. 1998. HSP70 exerts its antiapoptic function downstream of capsase-3-like proteases. EMBO J. 17:6124 - 6134.

Kishor PBK and Reddy GM. 1986. Retention and revival of regenerating ability by osmotic adjustment in long-term cultures of four varieties of rice. J. Plant Physiol. 126:49 54.

Kyo M and Harada H. 1986. Control of the developmental pathway of tobacco pollen in vitro. Planta 168:427 - 432.

Kyo M, Yamaji N, Yuasa Y, Maeda T, and Fukui H. 2002. Isolation of cDNA coding for $\mathrm{NtEPb1-b3}$ marker proteins for pollen de-differentiation in a tobacco pollen culture system. Plant Sci 163:1055 - 1062. 
Kyo M, Hattori S, Yamaji N, Pechan P and Fukui H. 2003. Cloning and characterization of cDNAs associated with the embryogenic de-differentiation of tobacco immature pollen grains. Plant Sci 164(6):1057 - 1066.

Malik MR, Wang F, Dirpaul JM, Zhou N. Polowick PL, Ferrie AMR, Krochko JE. 2007. Transcript profiling and identification of molecular markers for early microspore embryogenesis in Brassica napus. Plant Physiology 144:134 - 154.

Maluszynski M, Kasha KJ, Szarejko I 2003. Published double haploid protocols in plant species. In: Maluszynski M, Kasha K, Forster BP, Szarejko I (eds.). Doubled haploid production in crop plants. A manual. Kluwer, Dordrecht, pp 309 - 335.

Maraschin SF, Priester W de, Spaink HP and Wang M. 2005a. Androgenic switch: an example of plant embryogenesis from the male gametophyte perspective. Journal of Experimental Botany 56:1711 - 1726.

Maraschin SF, Vennik M, Lamers GEM, Spaink HP, Wang M. 2005b. Time-lapse tracking of barley androgenesis reveals position-determined cell death within pro-embryos. Planta 220:531 - 540.

Maraschin SF, Caspers M, Potokina E, Wulfert F, Graner A, Spaink HP and Wang M. 2006. cDNA array analysis of stress-induced gene expression in barley androgenesis. Physiologia Plantarum 127:535 - 550.

Murashige T and Skoog F. 1962. A revised medium for rapid growth and bioassays with tobacco tissue cultures. Physiol. Plantarum 15:473 - 497.

Nitsch JP and Nitsch C. 1969. Haploid plants from pollen grains. Science 163:85 - 87.

Obert B, Barnabas B. 2004. Colchicine induced embryogenesis in maize. Plant Cell Tissue and Organ Culture 77:283 - 285.

Okamoto Y, Kinoshita A, Satake T. 2001. Enhancement of the frequency of callus formation and plant regeneration from rice anther culture by alternating temperature. Breed Res 3:87 - 94 (in Japanese).

Palmer CED and Keller WA. 2005. Overview of haploidy. In: Haploids in Crop Improvement II. Ed. CE Palmer, WA Keller and KI Kasha. Biotechnology in Agriculture and Forestry Vol. 56, Springer Verlag, Berlin, Heidelberg pp: 3 - 7.

Pauls KP, Chan J, Woronuk G, Schulze D, Brazolot J. 2006. When microspores decide to become embryos - cellular and molecular changes. Can J Bot Rev Can Bot 84:668 678.

Raina SK and Irfan ST. 1998. High frequency embryogenesis and plantlet regeneration from isolated microspores of indica rice. Plant Cell Rep. 17:957 - 962.

Raina SK and Zapata FJ. 1997. Enhanced anther culture efficiency in indica rice (Oryza sativa L.) through modification of the culture media. Plant Breed 116(4):305 - 315.

Razdan MK. 2003. Introduction to plant tissue culture. 2nd Ed. Science Publishers Inc. Enfield, NH, USA.

Reynolds TL and Crawford RL. 1997. Effects of light on the accumulation of abscisic acid and expression of an early cysteine-labeled metallothionein gene in microspores of Triticum aestivum during induced embryogenic development. Plant Cell Rep 16(7):458 - 463.

Schoffl F, Prandl R and Reindl A. 1998. Regulation of heat shock response. Plant Physiology 117:1135 - 1141 . 
Segui-Simarro JM and Nuez F. 2008. How microspores transform into haploid embryos: changes associated with embryogenesis induction and microspore-derived embryogenesis. Physiologia Plantarum 134:1 - 12.

Sentenac H, Bonneaud N, Minet M, Lacroute F, Salmon JM, Gaymard F, Grignon C. 1992. Cloning and expression of a plant potassium ion transport system. Science 256:663 $-665$.

Shariatpanahi ME, Bal U, Heberle-Bors E, and Touraev A. 2006. Stresses applied for the reprogramming of plant microspores towards in vitro embryogenesis. Physiologia Plantarum 127:519 - 534.

Silva TD. 2010. Indica rice anther culture: can the impasse be surpassed? Plant Cell Tissue and Organ Culture 100:1 -11.

Silva TD and Ratnayake WJ. 2009. Anther culture potential of indica rice varieties, Kurulu thuda and Bg 250. Tropical Agricultural Research and Extension 12(2):53 - 56.

Simmonds DH and Keller WA. 1999. Significance of preprophase bands of microtubules in the induction of microspore embryogenesis in Brassica napus. Planta 208:383 - 391.

Smykal P. 2000. Pollen embryogenesis - the stress mediated switch from gametophytic to sporophytic development. Current status and future prospects. Biol. Plant. 43:481 489.

Sternlicht H, Ringel I, Szasz J. 1983. Theory for modeling the copolymerization of tubulin and tubulin-colchicine complex. Biophys J 42:255 - 267.

Sunderland N. 1971. Anther culture: a progress report. Sci Prog (Oxford) 59:527 - 549.

Tanaka M. 1973. The effect of centrifugal treatment on the emergence of plantlets from cultured anther of tobacco. Japan J Breed 23:171 - 174.

Toureav A, Illham A, Vincente O, Heberle-Bors E (1996a). Stress induced microspore embryogenesis from tobacco microspores: an optimized system for molecular studies. Plant Cell Reports 15:561 - 565.

Toureav A, Indrianto A, Wratschko I, Vincente O, Heberle-Bors E (1996b). Efficient microspore embryogenesis in wheat (Triticum aestivum L.) induced by starvation at high temperatures. Sex Plant Reprod 9:209 - 215.

Touraev A, Pfosser M, Vicente O, Heberle-Bors E. 1996. Stress as the major signal controlling the developmental fate of tobacco microspores: towards a unified model of induction of microspore/pollen embryogenesis. Planta 200:144 - 152.

Touraev A, Vicente O and Heberle-Bors E. 1997. Initiation of micropsore embryogenesis by stress. Trends in Plant Science 2(8):297 - 302.

Vrinten PL, Nakamura T, Kasha KJ. 1999. Characterization of cDNAs expressed in the early stages of microspore embryogenesis in barley (Hordeum vulgare L.). Plant Mol. Biol. 41(4):455 - 463.

Wallin M, Stromberg E. 1995. Cold-stable and cold-adapted microtubules. International Review of Cytology 157:1 - 31.

Wedzony M, Forster BP, Zur I, Golemiec E, Szechynska-Hebda M, Dubas, Gotebiowska G. 2009. Progress in doubled haploid technology in higher plants. In: Touraev A, Forster BP, Jain SM, (eds.). Advances in haploid production in higher plants. Springer, Berlin, pp $1-34$.

Yan J, Xue Q and Zhu J. 1996. Genetic studies of anther culture ability in rice (Oryza sativa). Plant Cell Tissue and Organ Culture 45:253 - 258. 
Zaki MAM, Dickinson HG. 1991. Microspore-derived embryos in Brassica: the significance of division symmetry in pollen mitosis I to embryogenic development. Sexual Plant Reproduction 4: 48 - 55.

Zarsky V, Garrido D, Eller N, Tupy J, Vicente O, Schoffl F and Heberle-Bors E. 1995. The expression of a small heat shock gene is activated during induction of tobacco pollen embryogenesis by starvation. Plant Cell Environ. 18:139 - 147.

Zhao JP, Simmonds DH, Newcomb W. 1996. Induction of embryogenesis with colchicine instead of heat in microspores of Brassica napus L. cv. Topas. Planta 189:433 - 439. 


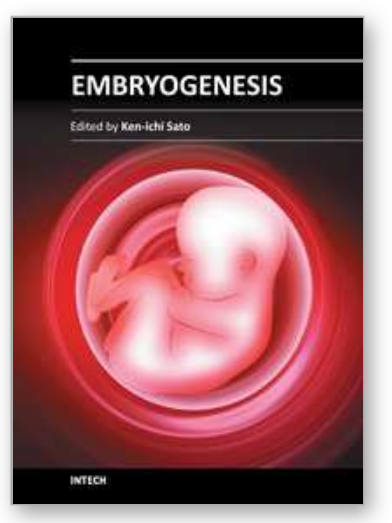

\author{
Embryogenesis \\ Edited by Dr. Ken-Ichi Sato
}

ISBN 978-953-51-0466-7

Hard cover, 652 pages

Publisher InTech

Published online 20, April, 2012

Published in print edition April, 2012

The book "Embryogenesis" is a compilation of cutting edge views of current trends in modern developmental biology, focusing on gametogenesis, fertilization, early and/or late embryogenesis in animals, plants, and some other small organisms. Each of 27 chapters contributed from the authorships of world-wide 20 countries provides an introduction as well as an in-depth review to classical as well as contemporary problems that challenge to understand how living organisms are born, grow, and reproduce at the levels from molecule and cell to individual.

\title{
How to reference
}

In order to correctly reference this scholarly work, feel free to copy and paste the following:

Tara D. Silva (2012). Microspore Embryogenesis, Embryogenesis, Dr. Ken-Ichi Sato (Ed.), ISBN: 978-953-510466-7, InTech, Available from: http://www.intechopen.com/books/embryogenesis/microspore-embryogenesis

\section{INTECH}

open science | open minds

\author{
InTech Europe \\ University Campus STeP Ri \\ Slavka Krautzeka 83/A \\ 51000 Rijeka, Croatia \\ Phone: +385 (51) 770447 \\ Fax: +385 (51) 686166 \\ www.intechopen.com
}

\author{
InTech China \\ Unit 405, Office Block, Hotel Equatorial Shanghai \\ No.65, Yan An Road (West), Shanghai, 200040, China \\ 中国上海市延安西路65号上海国际贵都大饭店办公楼405单元 \\ Phone: +86-21-62489820 \\ Fax: +86-21-62489821
}


(C) 2012 The Author(s). Licensee IntechOpen. This is an open access article distributed under the terms of the Creative Commons Attribution 3.0 License, which permits unrestricted use, distribution, and reproduction in any medium, provided the original work is properly cited. 